\title{
Endocrine, paracrine, and autocrine placental mediators in labor
}

\author{
Zoe Iliodromiti, ${ }^{1}$ Nikolaos Antonakopoulos, ${ }^{2}$ Stauros Sifakis, ${ }^{3}$ Panagiotis Tsikouras, ${ }^{4}$ \\ Angelos Daniilidis, ${ }^{5}$ Kostantinos Dafopoulos, ${ }^{6}$ Dimitrios Botsis, ${ }^{1}$ Nikolaos Vrachnis ${ }^{1}$
}

\begin{abstract}
12nd Department of Obstetrics and Gynecology, University of Athens Medical School, Aretaieio Hospital, ${ }^{2} 1$ st Department of Obstetrics and Gynecology, University of Athens Medical School, Alexandra Hospital, Athens, ${ }^{3}$ Department of Obstetrics and Gynecology, University Hospital of Heraklion, Heraklion, Crete, ${ }^{4}$ Department of Obstetrics and Gynecology, University Hospital of Alexandroupolis, Democritus University of Thrace, Alexandroupoli, ${ }^{5}$ Department of Obstetrics and Gynecology, Hippokratio Hospital, Aristotle University of Thessaloniki, Thessaloniki, ${ }^{6}$ Department of Obstetrics and Gynecology, Medical School, University of Thessalia, Larissa, Greece
\end{abstract}

\begin{abstract}
Considering that preterm birth accounts for about 6-10\% of all births in Western countries and of more than $65 \%$ of all perinatal deaths, elucidation of the particularly complicated mechanisms of labor is essential for determination of appropriate and effective therapeutic interventions. Labor in humans results from a complex interplay of fetal and maternal factors, which act upon the uterus to trigger pathways leading gradually to a coordinated cervical ripening and myometrial contractility. Although the exact mechanism of labor still remains uncertain, several components have been identified and described in detail. Based on the major role played by the human placenta in pregnancy and the cascade of labor processes activated via placental mediators exerting endocrine, paracrine, and autocrine actions, this review article has aimed at presenting the role of these mediators in term and preterm labor and the molecular pathways of their actions. Some of the aforementioned mediators are involved in myometrial activation and preparation and others in myometrial stimulation leading to delivery. In the early stages of pregnancy, myometrial molecules, like progesterone, nitric oxide, and relaxin, contribute to the retention of pregnancy. At late stages of gestation, fetal hypothalamus maturation signals act on the placenta causing the production of hormones, including $\mathrm{CRH}$, in an endocrine manner; the signals then enhance paracrinically the production of more hormones, such as estrogens and neuropeptides, that contribute to cervical ripening and uterine contractility. These molecules act directly on the myometrium through specific receptors, while cytokines and multiple growth factors are also produced, additionally contributing to labor. In situations
\end{abstract}


leading to preterm labor, as in maternal stress and fetal infection, cytokines trigger placental signaling sooner, thus leading to preterm birth.

Key words: Activin, Corticotrophin releasing hormone (CRH), Follistatin, Inhibin, Interleukin-1 (IL-1), Neuropeptide Y (NPY), Neurokinine B (NKB), Oxytocin, Placental mediators, Preterm labor, Prostaglandins, Transforming growth factor $\alpha$ (TGF- $\alpha)$

\section{INTRODUCTION}

The human placenta plays a major role in pregnancy, not only transporting gas and nutrients from mother to fetus, but also producing brain, pituitary, gonadal and adrenocortical peptides, and steroid hormones, chemically identical to and biologically as active as their counterparts, along with cytokines and several growth factors. Moreover, these molecules usually exert multiple functions implicated in distant endocrine effects, cell to cell paracrine communication or effects on the same cells (autocrine effects). Via these mediators, the placenta is able to provide a favorable environment for the growing fetus during pregnancy and to initiate the cascade of events that lead to labor. ${ }^{1}$

The aim of this review article is to describe the role of placental mediators in term and preterm labor and the molecular pathways of their actions. We examined review articles and original research reports from 1990-2011 indexed in Pubmed and other medical databases to present an updated overview of placental factors involved in the activation of term and preterm labor and to elucidate their biological plausibility and mode of action via a critical appraisal. The delineation of these complicated mechanisms is the first step towards the ultimate goal, this being the prevention of preterm labor, which still complicates $10 \%$ of all pregnancies with short- and long-term consequences for the fetus and neonate and also comprises a major cause of perinatal morbidity and mortality.

The main placental mediators, their actions, and cross actions are reviewed. We discuss the pathway of human labor that is known to date, placing special emphasis on the additional or supplementary pathways that, in the case of preterm labor, trigger these events sooner than expected. Some actions are well established and others can be hypothesized by using experimental data, such as receptor topography.

\section{PLACENTAL MEDIATORS}

Placenta products can be divided into five categories: a) steroid hormones, b) hypothalamic-pituitary hormones, c) neuropeptides, d) growth factors, e) cytokines. ${ }^{2,3}$ The actions of mediators playing a main role in term and preterm labor are summarized in Table 1. Interestingly, some molecules are inducers for others possessing the same actions, thus enhancing the cascade of labor. Moreover, most of the molecules have multiple receptors in different sites of the maternal-placental-fetal unit as well as exerting complex endocrine, paracrine, and autocrine effects on those sites.

\subsection{Placental steroid hormones}

Steroid hormones produced by the placenta include the common female gonadal steroid hormones, progesterone and estrogens, mainly estriol, but also estradiol and estrone. The predomination of estrogen over progesterone occurs during the transition from early pregnancy to labor and delivery in humans. In other mammals the production of progesterone is decreased and is partially converted to estrogen via the enzyme 17 -hydroxylase. The human placenta lacks this enzyme, thus fetal dehydroepiandrosterone sulfate (DHEA-S) comes into play for the production of estrogen. ${ }^{1}$ The converting placental enzymes are 3-hydroxysteroid dehydrogenase and delta 4-5 isomerase. With progesterone receptors achieving desensitization and increased estrogen levels at term, estrogen-dependent molecules, like receptors and enzymes, induce labor. 
Table 1. Role of placental mediators in labor. Interactions, site of action, and endocrine, paracrine, and autocrine actions

\begin{tabular}{|c|c|c|c|c|}
\hline Molecule & Inducers (+) Inhibitors (-) & Location of receptors & Actions & Mode of action \\
\hline Estrogen & $\begin{array}{l}\text { DHEA-S }(+) \text { (humans) } \\
\text { Fetal cortisol }(+) \\
\text { (other mammals) }\end{array}$ & $\begin{array}{l}\text { Placenta } \\
\text { Decidua } \\
\text { Fetal membranes }\end{array}$ & $\begin{array}{l}\text { 仓 } \mathrm{CRH} \\
\text { 仓 } \mathrm{PG}\end{array}$ & $\mathrm{E}, \mathrm{P}$ \\
\hline Oxytocin & $\begin{array}{l}\operatorname{Activin}(+) \\
\text { Estrogen }(+)\end{array}$ & $\begin{array}{l}\text { Decidua } \\
\text { Myometrium }\end{array}$ & Uterine contractions & $\mathrm{E}, \mathrm{P}$ \\
\hline $\begin{array}{l}\text { CRH } \\
\text { Urocortins }\end{array}$ & $\begin{array}{l}\text { Oxytocin (+) } \\
\text { NPY (+) } \\
\text { IL-1 (+) } \\
\text { Prostaglandin (+) } \\
\text { Norepinephrine (+) } \\
\text { Angiotensin II (+) } \\
\text { Cortisol (+) } \\
\text { ACH (+) } \\
\text { PRG (-) } \\
\text { NO (-) }\end{array}$ & $\begin{array}{l}\text { Maternal pituitary } \\
\text { Fetal pituitary } \\
\text { Myometrium } \\
\text { Decidua } \\
\text { Fetal membranes } \\
\text { Placenta } \\
\text { Immune cells }\end{array}$ & $\begin{array}{l}\text { 仓 } \mathrm{ACTH} \& \text { endorphins } \\
\text { 仓 ACTH \& endorphins } \\
\text { Uterine contractions } \\
\text { 仓 } \mathrm{PG} \\
\text { 仓 } \mathrm{PG} \\
\text { 仓 ACTH \& blood vessel dilatation } \\
\text { 仓 Cytokines }\end{array}$ & $\mathrm{E}, \mathrm{P}$ \\
\hline NPY & $?$ & $\begin{array}{l}\text { Placenta } \\
\text { Myometrium }\end{array}$ & $\begin{array}{l}\text { ? 仓 } \mathrm{CRH} \\
\text { Uterine contractions }\end{array}$ & $\mathrm{P}, \mathrm{A}$ \\
\hline NKB & $?$ & $\begin{array}{l}\text { Placenta } \\
\text { Myometrium }\end{array}$ & $\begin{array}{l}\text { ? 仓 } \mathrm{CRH} \\
\text { Uterine contractions }\end{array}$ & $\mathrm{P}, \mathrm{A}$ \\
\hline Activin A & $\begin{array}{l}\text { Inhibin (-) } \\
\text { Follistatin (-) }\end{array}$ & $\begin{array}{l}\text { Placenta } \\
\text { Decidua } \\
\text { Fetal membranes }\end{array}$ & 仓 PRG & $\mathrm{P}, \mathrm{A}$ \\
\hline IL-1 & Bacterial \& viral infections & $\begin{array}{l}\text { Placenta } \\
\text { Decidua } \\
\text { Fetal membranes }\end{array}$ & $\begin{array}{l}\text { 仓 } \mathrm{CRH} \\
\text { 仓 } \mathrm{HCG} \\
\text { 仓 } \mathrm{PG}\end{array}$ & $\mathrm{P}$ \\
\hline TNF $-\alpha$ & Bacterial \& viral infections & $\begin{array}{l}\text { Placenta } \\
\text { Decidua } \\
\text { Fetal membranes }\end{array}$ & 仓 $\mathrm{PG}$ & $\mathrm{P}$ \\
\hline Prostaglandins & $\begin{array}{l}\text { Oxytocin (+) } \\
\text { CRH (+) } \\
\text { GnRH (+) } \\
\text { Activin (+) } \\
\text { IL-1, IL-6 (+) } \\
\text { TGF, EGF (+) }\end{array}$ & $\begin{array}{l}\text { Placenta } \\
\text { Myometrium } \\
\text { Cervical stroma }\end{array}$ & $\begin{array}{l}\text { 仓 } \mathrm{CRH} \\
\text { Uterine contractions } \\
\text { Cervical ripening }\end{array}$ & $\mathrm{P}$ \\
\hline
\end{tabular}

E: endocrine; P: paracrine; A: autocrine; CRH: corticotrophin releasing hormone.

\subsection{Hypothalamic-pituitary hormones produced by the placenta}

It is noteworthy that the placenta produces hormones that are known to be produced by neuroendocrine organs, such as the hypothalamus and pituitary gland. These hormones include human chorionic gonadotrophin (hCG), human placental lactogen (hPL), oxytocin, gonadotrophin-releasing hormone (GnRH), opioids, growth hormone-releasing hormone (GHRH), somatostatin, and corticotrophin releasing hormone (CRH).

GnRH stimulates hCG placental production which 
is induced by estrogen, cytokines, and other molecules, whereas hCG production is blocked by progesterone, opioids, and other hormones. This may explain why recurrent miscarriages occur in opioid-addicted pregnant women. ${ }^{2}$

Oxytocin placental production and oxytocin receptors are increased during pregnancy. Oxytocin acts on myometrium and decidual tissues resulting in uterine contractions and prostaglandins production, respectively. ${ }^{4}$

Corticotropin-releasing factor-like activity in human placental extracts has been reported since the 1980's., ${ }^{5,6}$ Women who go into preterm labor have higher levels of plasma CRH as early as 15-16 weeks compared with women who deliver at term. ${ }^{2,7}$ On the other hand, women delivering post-term have lower levels of plasma CRH. ${ }^{1}$ Lower CRH production early in pregnancy has utero-relaxing action, but these early $\mathrm{CRH}$ receptors later in pregnancy and near labor are desensitized by a kinase which is oxytocin-controlled. ${ }^{8}$ Before labor other "late" CRH receptors are expressed in fetal pituitary, fetal membranes, the deciduas, and the myometrium, which activate G-protein mediated pathways that lead to prostaglandins production and myometrial contractions. ${ }^{9}{ }^{910}$ Furthermore, the CRHbinding protein (CRH-BP), a $37 \mathrm{kD}$ protein produced in the placenta, liver, brain, and other sites, blocks the action of CRH early in pregnancy. The binding of $\mathrm{CRH}$ to $\mathrm{CRH}-\mathrm{BP}$ makes it biologically inactive and removes it from the circulation. Near term or in preterm labor, CRH-BP decreases coincidentally with the increase of $\mathrm{CRH}$ production, this enhancing its action. ${ }^{11,12}$

Very recently, molecules belonging to the family of $\mathrm{CRH}$, named urocortins, have been described. They bind to the same receptors as $\mathrm{CRH}$, their levels increase before labor, and they result in myometrial contractility in the same way, directly and indirectly, as $\mathrm{CRH} .{ }^{11,13}$

\subsection{Placental neuropeptides}

Two known neuropeptides produced by the placenta are neuropeptide Y (NPY) and neurokinine $\mathrm{B}$ (NKB). In humans, during pregnancy the placenta secretes NPY in the maternal and fetal circulation and in the amniotic fluid. Throughout gestation NPY levels do not change significantly; however, during labor NPY levels in all the above biological fluids progressively increase, with the highest levels occurring at the most advanced stages of labor, the latter verification confirming the role of NPY in labor and delivery. Immediately after delivery, NPY levels fall, this demonstrating its placental origin. NPY receptors are present in all peripheral cells of placental terminal villi, thus indicating that NPY possibly acts both ways: that is, there may be an enhancement of CRH production in an autocrine manner. Furthermore, NPY receptors also are identified in human myometrium. NPY binding on myometrial receptors contributes to uterine contractility through a pertussis toxin sensitive G-protein mediated pathway. This pathway starts from the NPY receptors and continues with inhibition of adenylate cyclase activity and increase of intracellular calcium levels (Figure 1). In vitro studies have shown involvement of NPY in regulation of uterine blood flow and uterine contractility. ${ }^{11}$

$\mathrm{NKB}$, another neuropeptide produced by the placenta, acts as a paracrine regulator of fetal placental vascular tone mainly causing relaxation of placental vessels. Moreover, it is a modulator of myometrial contractility, enhancing it when binding with its receptors (NKR) on myometrium. NKB concentration in maternal blood increases as pregnancy advances and decreases rapidly after delivery, this demonstrating its placental origin. NKB receptors belong to the G-protein-linked receptors family. NKB initiated pathways are similar to NPY receptor initiated pathways (Figure 2). Expression of placental NKB mRNA and of protein is higher in term labor than at elective cesarean section and even higher in preterm labor. ${ }^{11,14}$

\subsection{Placental growth factors}

The placenta is the source of numerous growth factors including inhibin, activin, follistatin, transforming growth factor $\alpha$ (TGF- $\alpha$ ), insulin-like growth factor (IGF), epidermal growth factor (EGF), fibroblast growth factor (FGF), platelet-derived growth factor (PDGF), and angiogenin.

Activin $\mathrm{A}$ is a disulfide-linked dimer that belongs to the transforming growth factor $\beta$ (TGF- $\beta$ ) superfamily. An increase of placental activin A production occurs in labor at term. Increased production also occurs at 31-34 weeks of gestation in cases that will 


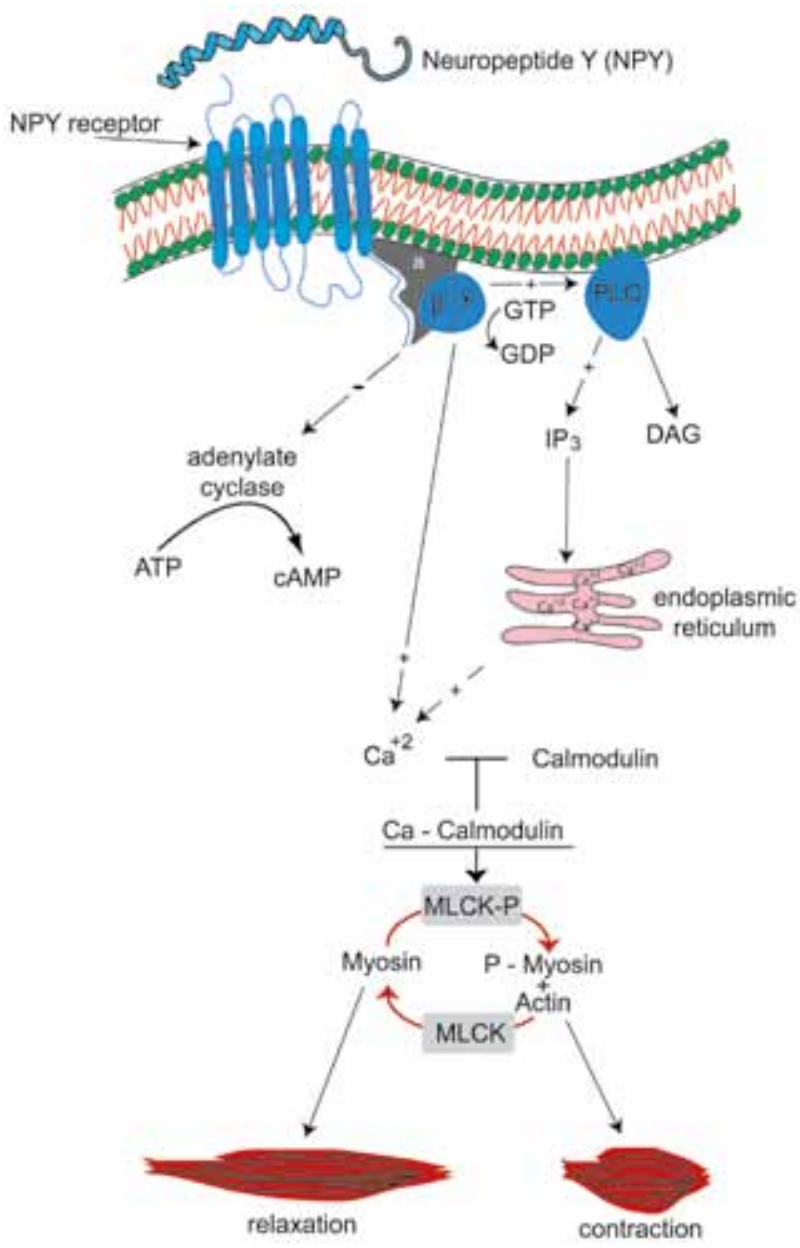

Figure 1. NPY binding to its receptors contributes to uterine contractility through a pertussis toxin sensitive G-protein mediated pathway. This pathway starts from the NPY receptors and continues with inhibition of adenylate cyclase activity and increase of intracellular calcium levels.

go into preterm labor, but there is no increase during preterm labor, although there is increased activin A mRNA expression at that time. ${ }^{15,16}$ Activin A enhances the production of prostaglandins and oxytocin in a paracrine manner in the placenta. Administration of inflammatory cytokines to gestational tissue was reported to result in increased activin A production, which may be relevant in cases of preterm delivery occurring secondarily to intrauterine infection. ${ }^{17}$ Activin A receptors are transmembrane heteromeric serine kinases that interact with and phosphorylate cytoplasmic SMAD2, which multimerizes with SMAD4 and translocates to the nucleus where these proteins can act as transcription factor complexes (Figure

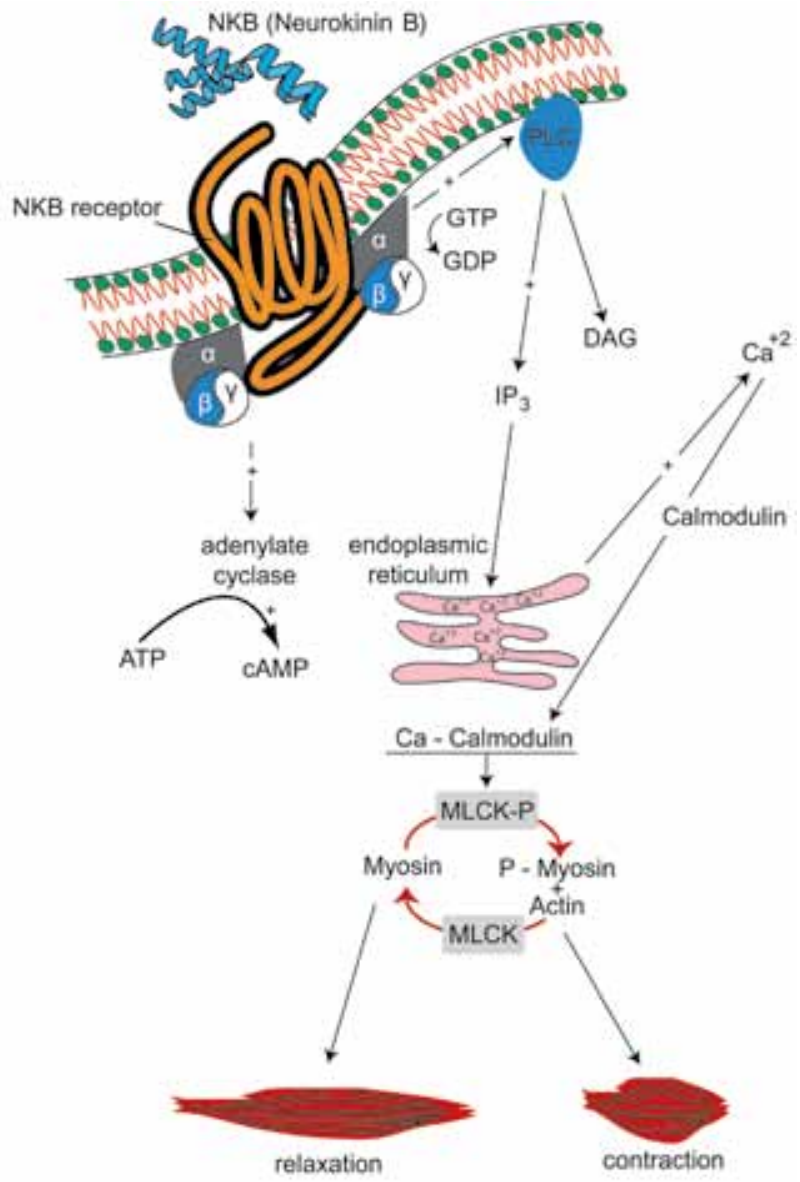

Figure 2. NKB receptors belong to the G-protein-linked receptors family. The NKR initiated pathway is similar to the NPY receptor pathway. The result of its action is an increase of intracellular calcium levels that enhance myometrial contractility. The difference of its action is the induction and not inhibition of a denylate cyclase.

3). ${ }^{11}$ The SMAD proteins are homologs of both the drosophila protein, mothers against decapentaplegic (MAD), and the Caenorhabditis elegans protein SMA, the name being a combination of the two aforementioned proteins. SMADs are intracellular proteins that transduce extracellular signals from TGF- $\beta$ ligands to the nucleus where they activate downstream TGF- $\beta$ gene transcription.

Inhibin and follistatin both inhibit activin $\mathrm{A}$, but their constant presence from early on and during pregnancy minimizes the possibility of their playing a role in labor (Figure 4), ${ }^{2,15}$ Another growth factor, angiogenin, displays increased second trimester amniotic fluid levels in pregnancies with higher risk 


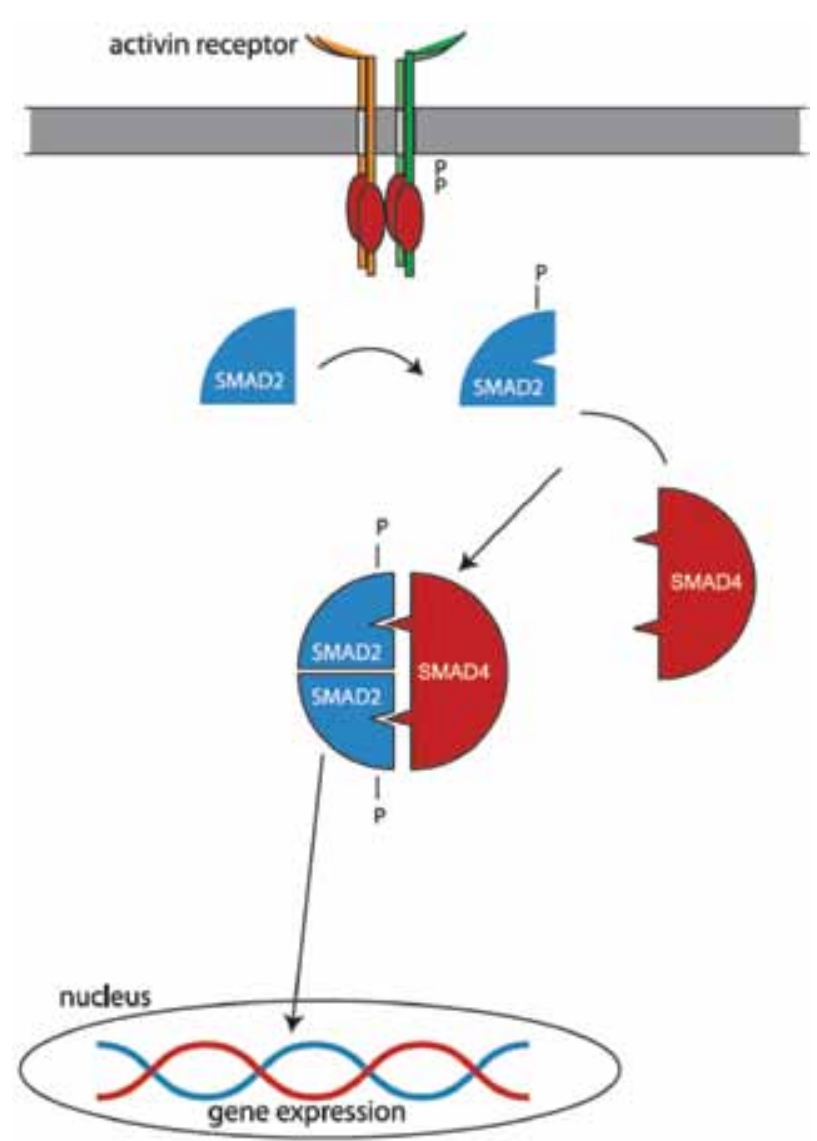

Figure 3. Activin A receptors are transmembrane heteromeric serine kinases that interact with and phosphorylate cytoplasmic SMAD2, which multimerizes with SMAD4 and translocates to the nucleus, where these proteins can act as transcription factor complexes.

of spontaneous preterm delivery. ${ }^{18}$

Other less studied placental growth factors are EGF, IGF, and TGF- $\alpha$. IGF production increases throughout pregnancy: though studies suggest that IGF mediates stretch-induced myometrial hypertrophy, further investigation is needed to precisely determine their possible role in labor. ${ }^{19}$ EGF and TGF- $\alpha$ seem to share the same receptors on the placenta, endometrium, and decidual and fetal membranes. Studies indicate that there is upregulation of epidermal growth factor receptors messenger RNA expression in myometrium and fetal membrane before and after the onset of labor. ${ }^{20}$ EGF and TGF- $\alpha$ also induce prostaglandin synthesis, but there is no significant increase in their production before labor, thus their role in labor is still in question., ${ }^{2,10}$
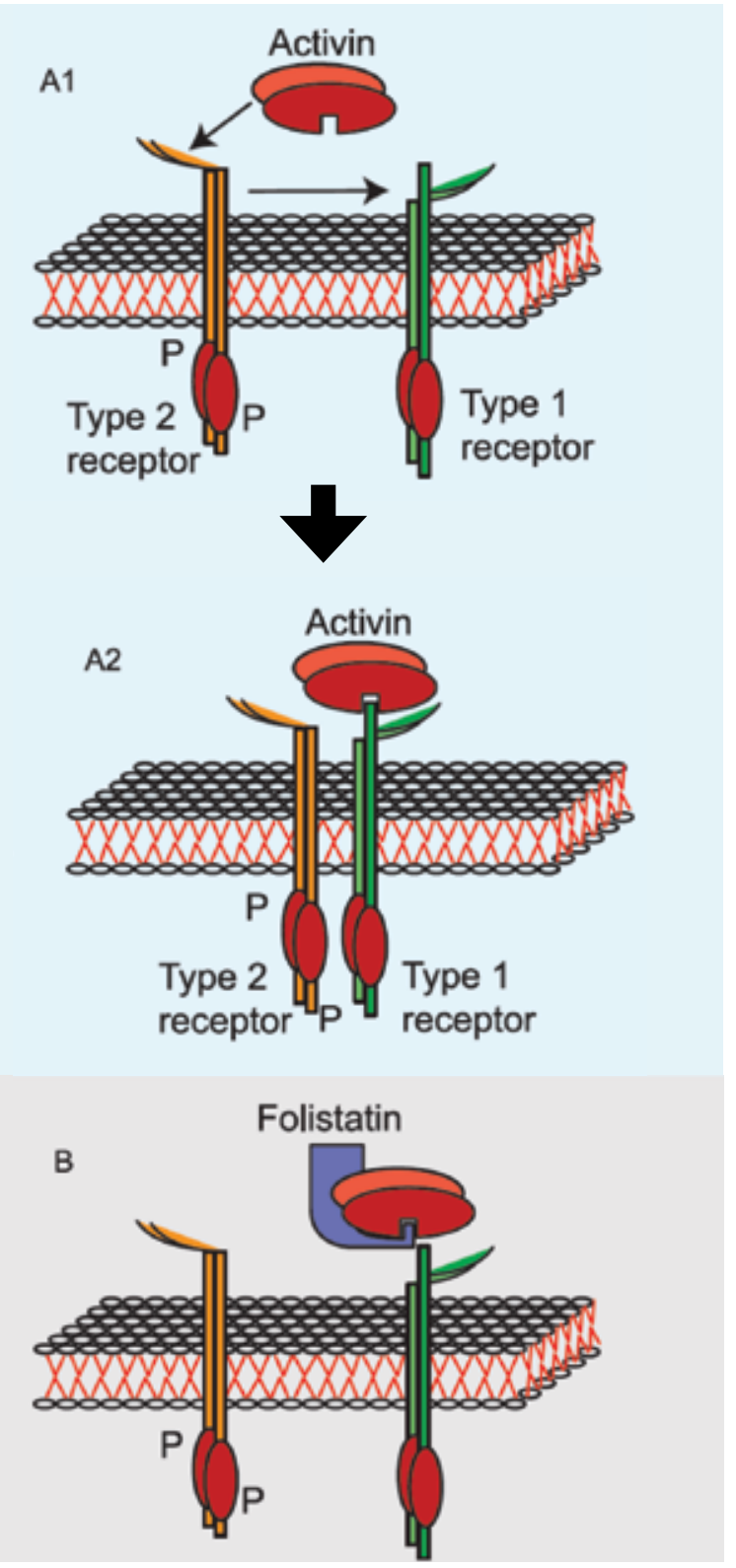

Figure 4. The inhibitory action of follistatin on activin. A1 and A2: Activin interaction with type 2 receptor enhances binding of type 1 receptor and formation of the active heteromeric receptor. B. Follistatin binds with activin so that the complex molecule cannot interact with activin type 2 receptor and the active heteromeric receptor cannot be formatted.

\subsection{Cytokines produced by placental leukocytes}

White blood cells located in the placenta secrete cytokines, including interleukin 1 (IL-1), interleukin 6 (IL-6), tumor necrosis factor $\alpha$ (TNF- $\alpha$ ), and interferon (IFN). Inflammatory cytokines, like IL-1 and TNF- $\alpha$, induce prostaglandins production and 
may thus account for preterm delivery in the setting of infection. ${ }^{10,21,22}$

Bacterial toxins, e.g. LPS (lipopolysaccharide $S$ ), act on decidual tissue to cause the production of TNF- $\alpha$ which acts in the amnion or the decidua to alter cell function, namely, cell growth or prostaglandin production or both. A variety of proteins produced in the decidua accumulate in the amniotic fluid. TNF- $\alpha$, however, is not present in amniotic fluid of normal pregnancies at any stage of gestation or during spontaneous labor at term. However, TNF- $\alpha$ is present in amniotic fluid of 4 out of 10 pregnancies complicated by preterm labor in which the membranes are intact; LPS is also present in the amniotic fluid. We cannot be sure that TNF- $\alpha$ is not produced in the decidua in some preterm labor pregnancies in which LPS is present in the amniotic fluid, although TNF- $\alpha$ has not to date been identified. In 6 out of 10 amniotic fluids in which LPS was present, TNF- $\alpha$ was not detected..$^{23}$ This could mean that TNF- $\alpha$ was not produced or else too little was transferred and accumulated in amniotic fluid to be detected. It is also observed that TNF- $\alpha$ is cytostatic, but not cytolytic, in human amnion cells. Amnion cells, therefore, are relatively unique because other normal cells commonly respond to TNF- $\alpha$ as a growth factor or, alternatively, they do not. Indeed, TNF- $\alpha$, while cytolytic or cytostatic in a number of tumor cells, usually does not inhibit growth in normal cells. The possibility thus exists that in the amnion, LPS or some other bacterial factor acts on macrophage-like decidual cells (or macrophages of the decidua or both) to cause the production of TNF- $\alpha$, which, in turn, may act to inhibit growth of the amnion, a process that may favor rupture of the membranes. TNF- $\alpha$ may also act in vivo, as it does in vitro, to stimulate the production of $\mathrm{PGF}_{2 \alpha}$ by the decidua and PGE2 by the amnion.

The decidua, as well as endometrial stromal cells, also produces IL-1. The concentration of IL- 1 in amniotic fluid increases during spontaneous parturition and increases even more dramatically during preterm labor complicated by infection. IL-1 acts on the decidua and endometrial stromal cells to augment $\mathrm{PGF}_{2 \alpha}$ formation. ${ }^{23}$ Moreover, IL- 1 and TNF- $\alpha$ stimulate the activity of the transcriptional factor NF- $x$ B (Nuclear Factor $x \mathrm{~B}$ ) in the uterus. NF- $x$ B plays a significant role in "functional" progesterone withdrawal, which is required for the initiation of labor. NF- $x \mathrm{~B}$ also stimulates prostaglandin synthesis and regulates matrix metalloproteinase expression, connexin-43, and oxytocin receptor. IL- 1 additionally induces production of $\mathrm{CRH}$ receptors and seems to have a synergic action with EGF. ${ }^{10}$

Other cytokines with a possible role in preterm labor are granulocyte colony stimulating factor, IL-6, and IL-8. ${ }^{3}$ IL- 1 and IL- 6 enhance endometrial CRH gene expression. ${ }^{24}$ IL-1 induces CRH receptor expression and function, contributing to a preparatory contractile environment necessary for the initiation of labor. IL- 6 also induces production of metalloproteinases that promote cervical ripening and rupture of membranes, as observed in ex vivo studies. ${ }^{25}$

\section{LABOR AND DELIVERY}

Throughout most of pregnancy, some low frequency, weak, and poorly coordinated contractions (Braxton-Hicks) occur. Coupling of actin and myosin prompts the occurrence of these contractions, this coupling resulting from phosphorylation of myosin by the enzyme myosin light-chain kinase (MLCK). The activation of MLCK is achieved via calmodulin, which is activated by intracellular calcium. Progesterone, prostacyclin, nitric oxide, relaxine, parathyroid hormone-related peptide, and other mediators increase cyclic adenosine or guanosine monophosphate molecules (cAMP or cGMP), which in turn inhibit the release of calcium from intracellular deposits. ${ }^{3}$

Moreover, there are no connexin gap junctions between myometrial cells during the period of Braxton Hicks contractions. ${ }^{26}$ Connexins, and mainly connexin 43 expression, are uterine stretch-induced and estrogen-induced, ${ }^{27}$ while progesterone blocks this expression. With progesterone receptors desensitization and increased estrogen levels at term of pregnancy, connexin gap junctions are massively increased.

The role of the placenta, by means of endocrine and paracrine mediators, is the synchronization of fetal maturation with parturition. ${ }^{10}$ Parturition has two stages, myometrial activation (stage 1 ) and myometrial stimulation (stage 2). Myometrial activation is achieved via myometrial oxytocin and prostaglandins receptors synthesis and induction of myometrial cells 
gap junctions in response to estrogen. ${ }^{10}$ Myometrial stimulation comes about through oxytocin and prostaglandins at the time that they bind to their receptors, with or without the combined action of mediators like neuropeptides and cytokines.

\subsection{Progesterone withdrawal in labor}

In humans, progesterone levels remain high throughout pregnancy and during labor. This has led to the hypothesis of a "functional" progesterone withdrawal, mentioned above. There are two major isoforms of progesterone receptor, PR-A and PR-B, which belong to the nuclear receptor superfamily, as well as many other isoforms which have so far given evidence of being less significant. PR-B is the main receptor for the nuclear signal transduction of progesterone. The expression of less sensitive isoforms possibly contributes to the "functional" withdrawal of progesterone before labor. ${ }^{28,29}$

The binding of progesterone to $\mathrm{PR}-\mathrm{C}$, which is a soluble form of the receptor, may sequester available progesterone away from PR-B and thereby diminish its biological effect. In a study of women in labor, PR-C protein levels were increased in cytoplasmic fractions of fundal myometrial cells. A reduction of progesterone nuclear coactivators has also been noticed pointing to the "closing" of chromatin structure and the reduced expression of PR-responsive genes as a possible mechanism for the initiation of labor. ${ }^{28}$ Finally, transcriptional factor NF- $x \mathrm{~B}$, which is involved in the synthesis of a large number of proinflammatory mediators such as cytokines, antagonizes progesterone in reproductive tissues during labor. ${ }^{28}$

\subsection{Placental CRH and the fetal hypothalamic- pituitary-adrenal axis}

The increase of oxytocin and prostaglandins receptors is signaled by the fetal hypothalamic-pituitaryadrenal (HPA) axis. ${ }^{30}$ Once fetal maturity is reached, the fetal hypothalamus and placenta secrete $\mathrm{CRH}$, which releases adrenocorticotropic hormone (ACTH) from fetal pituitary and fetal adrenals which produce cortisol and DHEA-S, the latter being aromatized to estrogens by the placenta. ${ }^{12}$ Fetal cortisol is essential for maturation of fetal organs, and especially the respiratory system, needed for extrauterine life. Increased cortisol levels promote the production of prostaglandins from the placenta, through prosta- glandin synthetase (PGS), in an estrogen-dependent manner. ${ }^{8,22,31}$ In sheep, placenta prostaglandins stimulate $\mathrm{P} 450$, resulting in increased placental estrogen synthesis. ${ }^{8}$

Placental CRH synthesis is stimulated by the produced fetal cortisol (positive feedback mechanism). ${ }^{10}$ A difference exists between placental and hypothalamic $\mathrm{CRH}$, since placental secretion is stimulated and fetal hypothalamic secretion is depressed by cortisol. Thus, although fetal CRH production may be reduced, placental $\mathrm{CRH}$ is increased. Moreover, the potential for fetal cortisol negative feedback action on fetal ACTH production is reduced by increased production of corticosteroid-binding globulin (CBG) at the end of pregnancy. Placental estrogens also induce the expression of the PGS and, in turn, the production of prostaglandins in chorion and amnion cells. Furthermore, placental estrogens enhance placental CRH production, this forming a second positive feedback loop. ${ }^{10}$

Prostaglandin dehydrogenase (PGDH) is induced by progesterone and downregulated by cortisol. ${ }^{31}$ Progesterone "functional" withdrawal reduces the activity of progesterone and increases the level of expression of estrogen receptors and estrogen activity on the myometrium. As a result, there is an increase in production of estrogen-dependent molecules, such as oxytocin receptors and prostaglandins, which promote uterine contractility. Activated prostaglandins receptors elevate intracellular calcium by blocking cAMP. They also enhance the production of cervix metalloproteinases to promote cervical ripening and decidual and fetal membrane activation. ${ }^{8}$ The initiation of this cascade seems to be placental production of $\mathrm{CRH}^{32}$

\subsection{Prostaglandins in labor and delivery}

There is considerable evidence in support of the likelihood that prostaglandins serve as the mediators (uterotonins) of the myometrial contractions experienced by women in labor. This evidence can be summarized as follows: (a) the administration of prostaglandins (intraamniotically, vaginally or intravenously) in human pregnancy leads to the onset of myometrial contractions and delivery at any stage of gestation; (b) the administration of inhibitors of prostaglandin synthesis to pregnant women is asso- 
ciated with prolonged gestation and an increase in the time interval for intraamniotic hypertonic saline induction of abortion; and (c) the concentrations of prostaglandins in amniotic fluid and in maternal plasma and urine are increased during parturition. The levels of PGE2 and $\mathrm{PGF}_{2 \alpha}$ in amniotic fluid increase strikingly during labor. ${ }^{23}$

Prostaglandins, mainly PGE2 and to a lesser extent $\mathrm{PGF}_{2 \alpha}$, seem to be the endpoint of the $\mathrm{CRH}$ cascade and characterize the action of most of the molecules that participate in term and preterm labor mechanisms. However, they also enhance their own production. They decrease the activity of placental $11 \beta$-HSD-2, the enzyme that converts cortisol, resulting in a further increase in local cortisol concentrations, this representing another positive feedback mechanism. ${ }^{8}$ Moreover, PGE2 stimulates fetal CRH production, yet a further positive feedback loop. ${ }^{31}$

A remarkable feature of prostaglandins is that when they bind with receptors type 1 and 3, which exist in the upper segment of the uterus, they cause contractility, but when they bind with receptors types 2 and 4, which exist in the lower segment of the uterus, they cause relaxation, a heterogeneity of the receptors that is genetically controlled. This constitutes a well established part of the mechanism of labor. The mechanisms discussed above are shown in Figure 5.

\section{PRETERM LABOR}

The greatest single cause of newborn morbidity and mortality is preterm birth. ${ }^{33,34}$ Well known common causes leading to preterm birth include stress, systemic or maternal genital tract infections, placental ischemia or vascular lesions, and uterine overdistension. ${ }^{35,36}$ It is reasonable to hypothesize that under these circumstances the placental "clock" is triggered sooner than normal to initiate the cascade of events leading to labor.

\subsection{Stress}

The placenta is responsive to maternal stress. ${ }^{37}$ $\mathrm{CRH}$ is released from cultured human placental cells in a dose-dependent manner in response to all major biological effectors of stress, such as cortisol, catecholamines, oxytocin, angiotensin 2, and IL-1., 70 Thus, in preterm delivery it may be the maternal
HPA axis and the sympatho-adrenergic system that starts the placental CRH cascade. Activation of the fetal HPA axis can occur in an adverse intrauterine environment, like compromised uteroplacental blood flow and other conditions of fetal hypoxemia or infection. ${ }^{8,38}$

\subsection{Infection and inflammation}

Microarray and suppression-subtractive hybridization studies have demonstrated an upregulation of a vast number of proinflammatory genes in fetal membranes, myometrium, and the cervix with the onset of labor ${ }^{39}$ Such upregulation is demonstrated by an influx of inflammatory cells into the uterus and increased expression of proinflammatory cytokines. ${ }^{40}$

At term, this inflammatory response may be triggered by the maturing fetal lung, which produces increased surfactant lipid and protein, leading to activation of macrophages in the amniotic fluid and increased inflammatory response in the uterus. ${ }^{41}$

Bacterial toxins like LPS, originating in microorganisms in uterine or extrauterine tissues, may act on the macrophage-like decidua to initiate a series of events that culminate in preterm labor, possibly together with premature rupture of the fetal membranes. Evidence in support of this hypothesis is that more than 40 years ago it was shown that the administration of LPS to pregnant animals caused abortion or premature parturition. Moreover, in LPS-treated animals, abortion or preterm delivery is associated with decidual hemorrhage and necrosis. Finally, LPS acts on monocytes and macrophages to instigate the production of prostaglandins, TNF- $\alpha$, and IL-1. ${ }^{23}$

Inflammation is a critical trigger for the initiation of term and preterm labor, with NF- $x \mathrm{~B}$ being a transcriptional factor implicated in proinflammatory stimuli signaling. IL- 1 and TNF- $\alpha$ stimulate NF- $x$ B activity in the uterus. NF- $x \mathrm{~B}$ also stimulates prostaglandin synthesis and regulates matrix metalloproteinase expression, connexin-43, and the oxytocin receptor. As already mentioned, NF- $x \mathrm{~B}$ is also related to a "functional" progesterone withdrawal in the human myometrium. ${ }^{28}$

Inflammatory cytokines, like IL-1 and TNF- $\alpha$, also induce prostaglandin production via upregulation of PGS synthetase and downregulation of PGDH and 


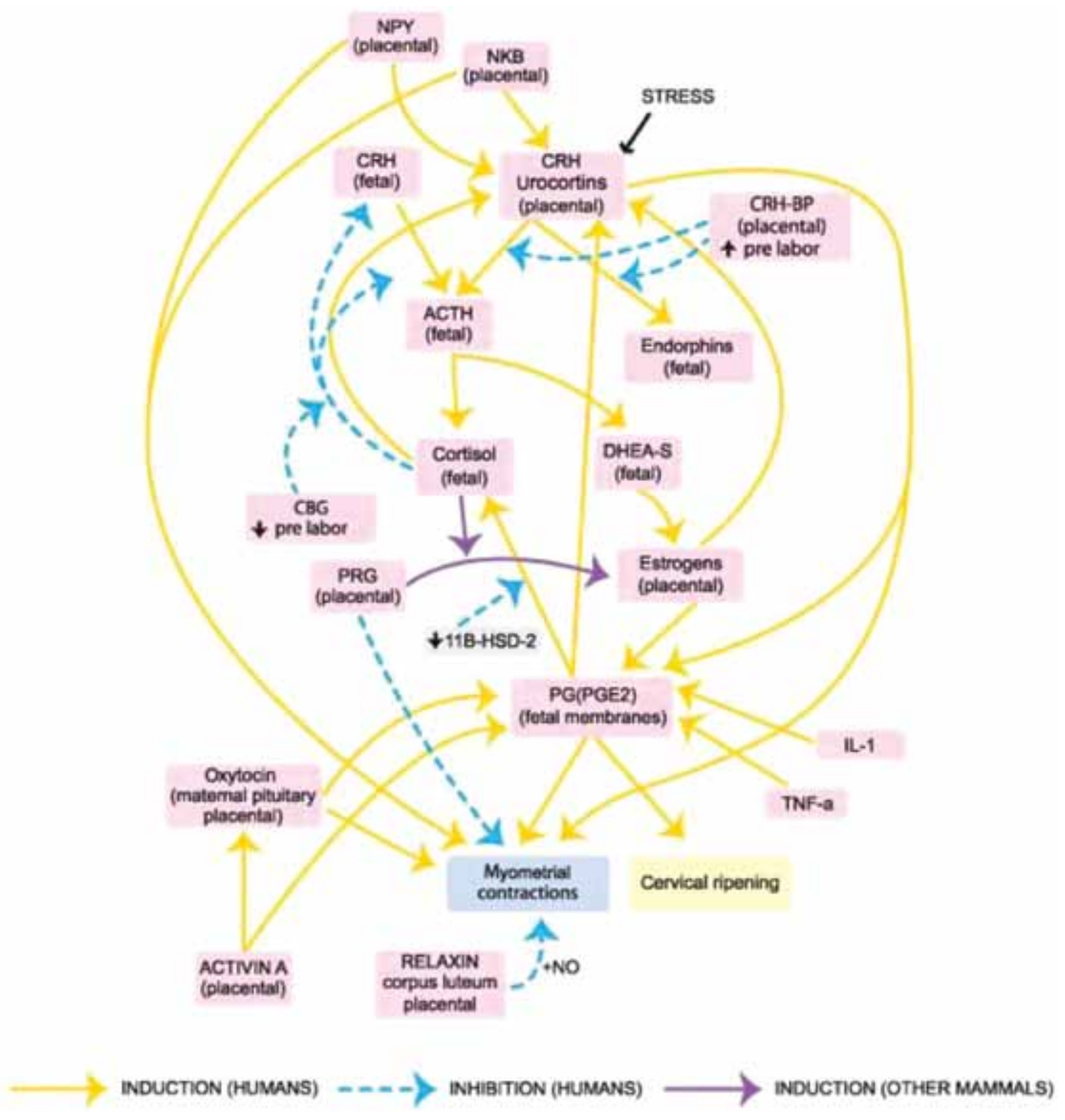

Figure 5. Pathways leading to labor. The main pathway starts from placental CRH, exploits fetal DHEA-S to produce estrogen environment and, through prostaglandins, results in myometrial contractions and cervical ripening, thus inducing labor. A variety of mediators interact in complex ways producing positive feedback loops of the main pathway:

- placental $\mathrm{CRH} \rightarrow$ fetal $\mathrm{ACTH} \rightarrow$ fetal cortisol $\rightarrow$ placental $\mathrm{CRH}$

- placental CRH $\rightarrow$ fetal ACTH $\rightarrow$ fetal DHEA-S $\rightarrow$ estrogens $\rightarrow$ placental CRH

- placental CRH $\rightarrow$ fetal ACTH $\rightarrow$ fetal DHEA-S $\rightarrow$ estrogens $\rightarrow$ PGE2 $\rightarrow$ placental CRH

- placental CRH $\rightarrow$ fetal ACTH $\rightarrow$ fetal DHEA-S $\rightarrow$ estrogens $\rightarrow$ PGE2 $\rightarrow$ fetal cortisol $\rightarrow$ placental CRH.

These mediators feed-forward enhancing roots of the main pathway (NPY, NKB, IL-1, TNF- $\alpha$, stress mediators, like catecholamines) or the endpoint of labor (NPY, NKB, oxytocin, activin A, IL-1, TNF- $\alpha$ ).

thus may explain preterm delivery in the setting of infection. ${ }^{10,21,22}$

An interesting study demonstrated synthesization and secretion of TNF- $\alpha$ into the culture medium by human decidual cells and explants in response to treatment with LPS. LPS treatment also caused an increase in $\mathrm{PGF}_{2 \alpha}$ production by decidual cells and explants. ${ }^{23}$

Other cytokines with a possible role in preterm labor are granulocyte colony stimulating factor, IL-6, and IL-8. ${ }^{[5]}$ Meanwhile, CRH receptors have been identified in the syncytiotrophoblast, deciduas and 
endometrium. PGE2, IL-1, and IL-6 enhance endometrial CRH gene expression and IL-1 induces CRH receptor expression and function, contributing to a preparatory contractile environment essential for the initiation of labor. Nevertheless, when an infection is present the fetal HPA axis can also be activated, thus starting the cascade..$^{42,43}$

Recently, studies have shown a significant impact of chorioamnionitis on placental $\mathrm{CRH}$ and urocortins and their receptors, suggesting that placental expression of stress-related pathways is activated in infective processes. ${ }^{44}$ Even cervical incompetence manifesting as a case of preterm labor, mechanical causes excluded, may be related to infection and inflammation, as a shortened or damaged cervix would not be capable of impeding the ascent of bacteria.

\subsection{Abruption and ischemia}

The key molecule in preterm labor when placental abruption and ischemia is present, as in placental thrombosis, is thrombin. It has been determined that thrombin binds to receptors which increase intracellular calcium via G-protein coupling and phospholipase $\mathrm{C}$ activation. ${ }^{45}$ In vitro, and moreover in vivo, experiments have shown a significant reduction of myometrial contractility via administration of the thrombin inhibitor heparin. ${ }^{46}$ Finally, thrombin induces the production of metalloproteinases, which can cause cervical ripening and rupture of fetal membranes, and protease-activated receptors which stimulates myometrial contractions. ${ }^{47,48}$

\subsection{Overdistention}

In cases of uterine stretch, like multiple gestation or polyhydramnios, myometrial and amnion epithelial cells increase their expression of cyclooxygenase and prostaglandin synthesis. Again, NF- $\varkappa \mathrm{B}$ seems to be the key signaling element. ${ }^{49}$

\section{CONCLUSION}

Human placenta is seen to be both an intermediary barrier and an active messenger in the maternal-fetal dialog. It releases endocrine, paracrine, and autocrine factors which control secretion of regulatory or terminal-effector molecules. Coordinated action results in cervical ripening, myometrial contractility, and labor, placenta also being implicated in initiation of labor and in preterm labor. Meanwhile, placental $\mathrm{CRH}$ acts on the fetal pituitary-adrenal axis, stimulating adrenal production of DHEA-S and cortisol, while myometrial activation, achieved via activation of estrogen derived from fetal DHEA-S through placental enzymes, causes uterine contractions. Subsequently, with onset of late-gestation "functional" progesterone withdrawal, fetal cortisol production, developing in an estrogenic environment, leads to labor. Placental $\mathrm{CRH}$ also acts directly on myometrial cells via its receptors. Other placental mediators (e.g. neuropeptides produced before labor), binding to their own receptors in myometrium, enhance uterine contractility. Placental CRH-induced prostaglandin and molecules (e.g. oxytocin, placental neuropeptides), regulatory cytokines, and growth factors cause cervical ripening, rupture of fetal membranes, myometrial stimulation, and regular contractions. Cytokines (e.g. IL-1, IL-6, and TNF- $\alpha$ ) are involved in positive feedback of placental CRH production, while stress or infection can trigger the placental "clock" and prematurely initiate the cascade of labor.

Despite extensive research into the extremely complicated mechanisms of labor in numerous animal models and humans, full elucidation is still lacking because of broad human v. animal divergence of physiology. Future progress in this area will enable development of effective treatments for preterm delivery thereby reducing neonatal morbidity and mortality.

\section{REFERENCES}

1. Federenko IS, Wadhwa PD, 2004 Women's Mental Health During Pregnancy Influences Fetal and Infant Developmental and Health Outcomes. CNS Spectrums 9: 198-206.

2. Petraglia F, Florio P, Nappi C, Genazzani AR, 1996 Peptide Signaling in Human Placenta and Membranes: Autocrine, Paracrine and Endocrine Mechanisms. Endocr Rev 17: 156-186.

3. Reis FM, D'Antona D, Petraglia F, 2002 Predictive value of hormone measurements in maternal and fetal complications of pregnancy. Endocr Rev 23: 230-257.

4. Fuchs AR, Fuchs F, Husslein P, Soloff MS, Fernstrom MJ, 1982 Oxytocin receptors and human parturition: a dual role for oxytocin in the initiation of labor. Science 215: 1396-1398.

5. Shibasaki T, Odagiri E, Shizume K, Ling N, 1982 Corticotropin-releasing factor-like activity in human 
placental extracts. J Clin Endocrinol Metab 55: 384-386.

6. Frim DM, Emanuel RL, Robinson BG, et al, 1988 Characterization and gestational regulation of corticotrophinreleasing hormone messenger RNA in human placenta. J Clin Invest 82: 287-292.

7. McLean M, Smith R, 1999 Corticotropin-releasing hormone in human pregnancy and parturition. Trends Endocrinol Metab 10: 174-178.

8. Challis JRG, Sloboda DM, Alfraidy N, et al, 2002 Prostaglandins and mechanisms of preterm birth. Reproduction 124: 1-17.

9. Karteris E, Grammatopoulos D, Randeva H, Hillhouse EW, 2000 Signal transduction characteristics of the corticotropin-releasing hormone receptors in the fetoplacental unit. J Clin Endocrinol Metab 85: 1989-1996.

10. Carbillon L, Uzan M, Challier JC, Marviel P, Uzan S, 2000 Fetal-placental and decidual-placental units: role of endocrine and paracrine regulations in parturition. Fetal Diagn Ther 15: 308-318.

11. Torricelli M, Giovanelli A, Torres PB, et al, 2006 Endocrine and paracrine mechanisms in human placenta and fetal membranes in preterm birth. Preterm Birth 3: 35-41.

12. Reis FM, Fadalti M, Florio P, Petraglia F, 1999 Putative role of placental corticotrophin-releasing factor in the mechanisms of human parturition. J Soc Gynecol Investig 6: 109-119.

13. Pepels PP, Spaanderman ME, Bulten J, et al, 2009 Placental urocortins and CRF in late gestation. Placenta 30: 483-490.

14. Torricelli M, Giovannelli A, Leucci E, et al, 2007 Placental neurokinin B mRNA expression increases at preterm labor. Placenta 28: 1020-1023.

15. Keelan JA, Marvin KW, Sato TA, et al, 1999 Concentrations of activin A, inhibin A and follistatin in human amnion, choriodecidual and placental tissues at term and preterm. J Endocrinol 163: 99-106.

16. Plevyak MP, Lambert-Messerlian GM, Farina A, Groome NP, Canick JA, Silver HM, 2003 Concentrations of serum total activin A and inhibin A in preterm and term labor patients: a cross-sectional study. J Soc Gynecol Investig 10: 231-236.

17. Keelan JA, Zhou RL, Evans LW, Groome NP, Mitchell MD, 2000 Regulation of activin A, inhibin A, and follistatin production in human amnion and choriodecidual explants by inflammatory mediators. J Soc Gynecol Investig 7: 291-296.

18. Farina A, Carinci P, Di Luzio L, 1997 Angiogenin: a marker for preterm delivery in midtrimester amniotic fluid. Am J Obstet Gynecol 177: 483-484.

19. Shynlova O, Tsui P, Dorogin A, Lowell-Langille B, Lye SJ, 2007 Insulin-like growth factors and their binding proteins define specific phases of myometrial differentiation during pregnancy in the rat. Biol Reprod 76: 571-578.

20. Chen J, Zenq W, Wu J, 2000 Correlation between epider- mal growth factor receptor messenger RNA expression and the onset of labor. Zhonghua Fu Chan Ke Za Zhi 35: 29-31.

21. Bowen JM, Chamley L, Keelan JA, Mitchell MD, 2002 Cytokines of the placenta and extra-placental membranes: roles and regulation during human pregnancy and parturition. Placenta 23: 257-273.

22. Challis JRG, Lye SJ, Gibb W, Whittle W, Patel F, Alfaidy N, 2006 Understanding preterm labor. Ann NY Acad Sci 943: 225-234.

23. Casey ML, Cox SM, Beutler B, Milewich L, MacDonald PC, 1989 Cachectin/Tumor Necrosis factor-a formation in human decidua - potential role of cytokines in Infection-induced preterm labor. J Clin Invest 83: 430-436.

24. Vitoratos N, Mastorakos G, Kountouris A, Papadias K, Creatsas G, 2007 Positive association of serum interleukin-1beta and CRH levels in women with preterm labor. J Endocrinol Invest 30: 35-40.

25. Lee SY, Buhimschi IA, Dulay AT, et al, 2011 IL-6 trans-signaling system in intra-amniotic inflammation, preterm birth, and preterm premature rupture of the membranes. J Immunol 186: 3226-3236.

26. Garfield RE 1988 Structural and functional studies of the control of myometrial contractility and labour. In McNellis D, Challis JRG, MacDonald PC, Nathanielsz PW, Roberts JM (eds) The onset of labour: cellular and integrative mechanisms. Ithaca, NY: Perinatology Press; pp, 55-80.

27. Lye SJ, Ou CW, Teoh TG, et al, 1998 The molecular basis of labour and tocolysis. Fetal Matern Med Rev: 121-136.

28. Vrachnis N, Malamas FM, Sifakis S, Tsikouras P, Iliodromiti Z, 2012 Immune aspects and myometrial actions of progesterone and CRH in labor. Clin Dev Immunol 2012: 937618.

29. Vrachnis N, Malamas FM, Sifakis S, Deligeoroglou E, Iliodromiti Z, 2011 The oxytocin-oxytocin receptor system and its antagonists as tocolytic agents. Intl $\mathbf{J}$ Endocrinol 2011: 350546.

30. Liggins GC, Thorburn GD, 1994 Initiation of parturition. In Lamming GE (ed) Marshall's: Physiology of Reproduction. London, UK: Chapman and Hall; pp, 863-1002.

31. Challis JRG, Smith SK, 2001 Fetal endocrine signals and preterm labor. Biol Neonate 79: 163-167.

32. Gibb W, Challis JR, 2002 Mechanisms of term and preterm birth. J Obstet Gynaecol 24: 873-883.

33. Rush RW, Keirse MJNC, Howat P, Baum JD, Anderson AB, Turnbull AC, 1976 Contribution of preterm delivery to perinatal mortality. Br Med J 2: 965-968.

34. Vrachnis N, Karavolos S, Iliodromiti Z, et al, 2012 Impact of mediators present in amniotic fluid on preterm labour. In Vivo 26: 799-812.

35. Vrachnis N, Vitoratos N, Iliodromiti Z, Sifakis S, Deligeoroglou E, Creatsas G, 2010 Intrauterine inflam- 
mation and preterm delivery. Ann NY Acad Sci 1205: 118-122.

36. Malamitsi-Puchner A, Vrachnis N, Samoli E, et al, 2006 Investigation of midtrimester amniotic fluid factors as potential predictors of term and preterm deliveries. Mediators Inflamm 2006: 94381.

37. Wadhwa PD, Culhane JF, Rauh V, Barve SS, 2001 Stress and preterm birth: Neuroendocrine, immune/ inflammatory, and vascular mechanisms. Matern Child Health J 5: 119-125.

38. Vrachnis N, Malamitsi-Puchner A, Samoli E, et al, 2006 Elevated mid-trimester amniotic fluid ADAM-8 concentrations as a potential risk factor for preterm delivery. J Soc Gynecol Investig 13: 186-190.

39. Charpigny G, Leroy MJ, Breuiller-Fouche M, et al, 2003 A functional genomic study to identify differential gene expression in the preterm and term human myometrium. Biol Reprod 68: 2289-2296.

40. Young A, Thompson AJ, Ledingham M, et al, 2002 Immunolocalisation of proinflammatory cytokines in myometrium, cervix and fetal membranes during human parturition at term. Biol Reprod 66: 445-449.

41. Condon JC, Jeyasuria P, Faust JM, et al, 2004 Surfactant protein secreted by the maturing mouse fetal lung acts as a hormone that signals the initiation of parturition. Proc Natl Acad Sci USA 101: 4978-4983.

42. Gravett MG, Haluska GJ, Cook MJ, Novy MJ, 1996 Fetal and maternal endocrine responses to experimental intrauterine infection in rhesus monkeys. Am J Obst Gynecol 174: 1725-1733.

43. Gravett MG, Hitti J, Hess DL, Eschenbach DA, 2000
Intrauterine infection and preterm delivery: Evidence for activation of the fetal hypothalamic-pituitary-adrenal axis. Am J Obst Gynecol 182: 1404-1413.

44. Torricelli M, Novembri R, Bloise E, De Bonis M, Challis JR, Petraglia F, 2011 Changes in placental $\mathrm{CRH}$, urocortins, and $\mathrm{CRH}-$ receptor mRNA expression associated with preterm delivery and chorioamnionitis. J Clinl Endocrinol Metab 96: 534-540.

45. Bohm SK, McConalogue K, Kong W, Bunnett NW, 1998 Proteinase-activated receptors: new functions for old enzymes. News Physiol Sci 13: 231-240.

46. Elovitz MA, Ascher-Landsberg J, Saunders T, Phillippe M, 2000 The mechanisms underlying the stimulatory effects of thrombin on myometrial smooth muscle. Am J Obst Gynecol 183: 674-681.

47. Mackenzie AP, Schatz F, Krikun G, Funai EF, Kadner S, Lockwood CJ, 2004 Mechanisms of abruption-induced premature rupture of the fetal membranes: Thrombin enhanced decidual matrix metalloproteinase-3 (stromelysin-1) expression. Am J Obst Gynecol 191: 1996-2001.

48. Stephenson C, Lockwood C, Ma Y, Guller S, 2005 Thrombin-dependent regulation of matrix metalloproteinase (MMP-9) levels in human fetal membranes. Journal of Maternal-Fetal and Neonatal Medicine 18: 17-22.

49. Mohan AR, Soorana SR, Lindstrom TM, et al, 2007 The effect of mechanical stretch on cyclooxygenase type 2 and activator protein-1 and nuclear factor-kappa $\mathrm{B}$ activity in human amnion cells. Endocrinology 148: 1850-1857. 